\title{
Assessing the Cultivability of Bacteria and Fungi from Arable Crop Residues Using Metabarcoding Data as a Reference
}

\author{
Valérie Laval ${ }^{1,+}{ }^{\dagger}$ Lydie Kerdraon ${ }^{1,+}{ }^{\dagger}$, Matthieu Barret ${ }^{2}$, Anne-Lise Liabot ${ }^{2}$, Coralie Marais ${ }^{2}$, Benjamin Boudier ${ }^{1}$, \\ Marie-Hélène Balesdent ${ }^{1}$, Marion Fischer-Le Saux ${ }^{2}$ and Frédéric Suffert ${ }^{1, *} \mathbb{C}$ \\ 1 Université Paris-Saclay, INRAE, AgroParisTech, UMR BIOGER, 78850 Thiverval-Grignon, France; \\ valerie.laval@inrae.fr (V.L.); lydiekerdraon@gmail.com (L.K.); benjamin.boudier@gmx.fr (B.B.); \\ marie-helene.balesdent@inrae.fr (M.-H.B.) \\ 2 INRAE, Agrocampus Ouest, Université d'Angers, UMR IRHS, 49071 Beaucouzé, France; \\ matthieu.barret@inrae.fr (M.B.); anne-lise.liabot@inrae.fr (A.-L.L.); coralie.marais@inrae.fr (C.M.); \\ marion.le-saux@inrae.fr (M.F.-L.S.) \\ * Correspondence: frederic.suffert@inrae.fr \\ + These authors contributed equally to this work.
}

Citation: Laval, V.; Kerdraon, L.; Barret, M.; Liabot, A.-L.; Marais, C.; Boudier, B.; Balesdent, M.-H.; Fischer-Le Saux, M.; Suffert, F. Assessing the Cultivability of Bacteria and Fungi from Arable Crop

Residues Using Metabarcoding Data as a Reference. Diversity 2021, 13, 404. https://doi.org/10.3390/d13090404

Academic Editors:

David Johnston-Monje

and Alejandro Caro-Quintero

Received: 22 July 2021

Accepted: 24 August 2021

Published: 26 August 2021

Publisher's Note: MDPI stays neutral with regard to jurisdictional claims in published maps and institutional affiliations.

Copyright: (c) 2021 by the authors. Licensee MDPI, Basel, Switzerland. This article is an open access article distributed under the terms and conditions of the Creative Commons Attribution (CC BY) license (https:// creativecommons.org/licenses/by/ $4.0 /)$.

\begin{abstract}
This study combined culture-dependent (strain isolation plus molecular identification) and culture-independent (metabarcoding) approaches to characterize the diversity of microbiota on wheat and oilseed rape residues. The goal was to develop a methodology to culture microorganisms with the aim of being able to establish synthetic crop residue microbial communities for further study, i.e., testing potential interactions within these communities and characterizing groups of beneficial taxa that could be used as biological control agents against plant pathogens. We generated community-based culture collections. We adapted the isolation strategy to the potential differences in the spatial and temporal distribution of diversity between bacteria and fungi. We performed (i) a high-throughput isolation from few samples with no a priori for bacteria and (ii) a low-throughput isolation from several samples with a priori-i.e., morphotype selection-for fungi. Although isolation using a single medium did not allow us to characterize the microbiome as precisely as metabarcoding, the bacterial diversity (158 ASVs, 36 genera) was relatively higher than the fungal diversity (131 ASVs, 17 genera) known to be limited by competition for growth on non-selective solid media. Isolation and metabarcoding provided consistent and complementary information: they revealed several common but also specific ASVs, leading to close microbial community profiles of the most abundant fungal and bacterial taxa in residues. Finally, by empirically comparing the different profiles, we assessed the cultivability of the most abundant fungal and bacterial taxa obtained in metabarcoding.
\end{abstract}

Keywords: bacteria; crop residue; fungi; isolation; metabarcoding; microbiome; microbial community; oilseed rape; wheat

\section{Introduction}

Crop residues are the decaying parts of the crop plant that are not harvested [1]. They were recently described as an 'ecotone' by Kerdraon et al. [2], i.e., a boundary compartment between two biomes, the plant, and the soil. These residues, as a transient half-plant/half-soil compartment, constitute a key fully fledged microbial ecosystem worthy of the attention of microbiologists and plant disease epidemiologists. They are the main support for the phytopathogenic agents responsible for residue-borne plant diseases, but they also host several plant-beneficial microorganisms and make a significant contribution to agrosystem stability [3-5].

In recent years, our knowledge of the diversity of microbial communities in agrosystems has increased considerably through the development of whole-community metagenomic sequencing methods applied to the phyllosphere (e.g., [6]), rhizosphere (e.g., [7]), and, more recently, the 'residue sphere' [5]. However, the cultures of fungal and bacterial 
species from different ecological niches within a specific ecosystem is still indispensable: it complements molecular databases for taxonomic identification through a single-strain approach, making it possible to test whether the interactions between micro-organisms predicted by metagenomic sequencing (e.g., through the analysis of interaction networks [8]) actually occur. Isolating micro-organisms is also essential for assessing the efficacy of strains as potential biocontrol agents (e.g., [9-11]), with such tests often limited by the availability of representative microbial culture collections [12].

Nevertheless, a major bias is introduced if only the cultivable fraction is considered, as this precludes an exhaustive description of the microbial community $[13,14]$. For example, the fraction of cultivable bacteria in the phyllosphere may be much lower than that in other environments $[15,16]$, depending on the media used, the growth conditions, and the plant species (e.g., [17,18]). Several fungal endophytes or pathogens-e.g., rust pathogens [19] or Olpidium brassicae [20] - are present in plant tissues, but always missed by culturing approaches due to their obligate biotrophic lifestyle. It has also long been thought that only a very small fraction of soil micro-organisms can be isolated in vitro (e.g., $[9,16])$. Beyond our ability to characterize and compare fine diversity, it is unclear for the 'residue sphere' whether the most abundant taxa identified by metabarcoding correspond to those that appear most abundant by isolation.

The combination of metabarcoding and culture techniques provides a more complete view of the microbiota. Many comparisons have been made between the microbial population compositions obtained by culture-dependent (with or without single-strain molecular identification) and culture-independent (whole-community metagenomic or metabarcoding sequencing) methods, mostly for bacterial communities, in the contexts of human health (e.g., gut microflora [21-23]), food (e.g., cheese [24]), and plants (e.g., roots, leaves, and seeds $[6,14,25-27])$. Comparative studies focusing on the fungal fraction (e.g., the endophytic flora [28-30]), or even on both the bacterial and fungal fractions (e.g., root symbionts [31]), are less common. Crop residues with specific microbiota, composed of decay, phytopathogenic, or biocontrol microorganisms are very much the "poor relation" in analyses of this type, and this gap should be filled.

The structure of the microbiota associated with wheat and oilseed rape residues was already compared extensively by metabarcode sequencing by Kerdraon et al. [5]. The impact of seasonality and crop rotation on the residue microbiome was highlighted, with the replacement of plant-specific taxa-including pathogens and endophytes-by more generalist bacterial and fungal taxa originating from the soil. Moreover, the effect of the presence of Zymoseptoria tritici and Leptosphaeria maculans-two important residueborne fungal pathogens of wheat and oilseed rape, respectively [32,33] — on the residue microbiome was estimated by combining linear discriminant analyses and ecological network analyses $[34,35]$. Correlative approaches of this type provide original information about the impact of phytopathogenic microorganisms on a whole microbial community. They facilitate the identification of beneficial keystone taxa and assemblages beneficial to host plant health. However, determining causal relationships requires the prior isolation, typing, and storage of representative microbial strains from residues. In a second step, the impact of these strains on plant pathogen development can be tested using monospecies or more complex assemblages such as 'synthetic communities' (e.g., [36]).

The goal of the current study was to assess the cultivability of the most abundant fungal and bacterial taxa of wheat and oilseed rape residues as a prerequisite to establish synthetic communities and test potential interactions within these communities. To this end, we developed an integrated approach tailored to the 'residue sphere': (i) that modulates the sample size considering potential differences in the spatial and temporal distribution of diversity between bacteria and fungi [5], with a dedicated way of isolating on a single medium (high-throughput isolation from few samples with no a priori for bacteria; lowthroughput isolation from several samples with a priori-i.e., morphotype selection-for fungi); and (ii) that allows us to test, by comparing different microbial assemblage profiles, whether the most abundant taxa obtained in metabarcoding [5] could be isolated. 


\section{Materials and Methods}

\subsection{Overall Strategy}

Wheat $(\mathrm{W})$ and oilseed rape $(\mathrm{O})$ residues were collected from three field plots after two cropping seasons (2015-2016 and 2016-2017) of a wheat-oilseed rape rotation at the Grignon experimental station (Yvelines, France; $48^{\circ} 51^{\prime} \mathrm{N}, 1^{\circ} 58^{\prime} \mathrm{E}$ [5]). Each of the residues sampled was cut in two lengthwise, with one half used for microbial isolation and the other half for metabarcoding (Figure 1). Bacterial and fungal strains were treated separately: for bacteria, reduced sampling effort was coupled with high-throughput isolation, whereas, for fungi, broader sampling effort was coupled with low-throughput isolation. We thus considered potential differences in the spatial and temporal distribution of diversity, relatively higher for bacteria than for fungi in several ecosystems (e.g., [5,37-39]). A large number of bacterial strains was isolated by infusing and spreading the suspensions obtained from a small number of residue samples ( $n=3$ sets $\times 5$ pieces) after the first cropping season: a set $\left(\mathrm{W}_{\mathrm{M}}\right)$ of five pieces of wheat residue from a wheat monoculture plot, a set $\left(W_{R}\right)$ of five pieces of wheat residue from a plot under the wheat-oilseed rape rotation, and a set $\left(\mathrm{O}_{\mathrm{R}}\right)$ of five pieces of oilseed rape residue from a second plot under the wheat-oilseed rape rotation (Figures 1 and 2). Fungi were isolated by selecting a small number of fungal colonies from a large number of crop residue samples (12 from wheat and $4 \times 3$ from oilseed rape, so $n=90$ sets $\times 12$ pieces; see Figure 2 ) collected at three dates (October, December, and February) during the two cropping seasons (year). Strains were identified molecularly by barcoding targeting the $\mathrm{v} 4$ region of the gene encoding $16 \mathrm{~S}$ rRNA in a single MiSeq Illumina run for bacteria and Sanger sequencing of the ITS1-5.8S-ITS2 region with ITS1F-ITS4 primers for fungi (Figure 2).

Whole-community metabarcoding (high-throughput amplicon sequencing) was implemented targeting the gene encoding the 16S rRNA and the ITS1 region, respectively [5].
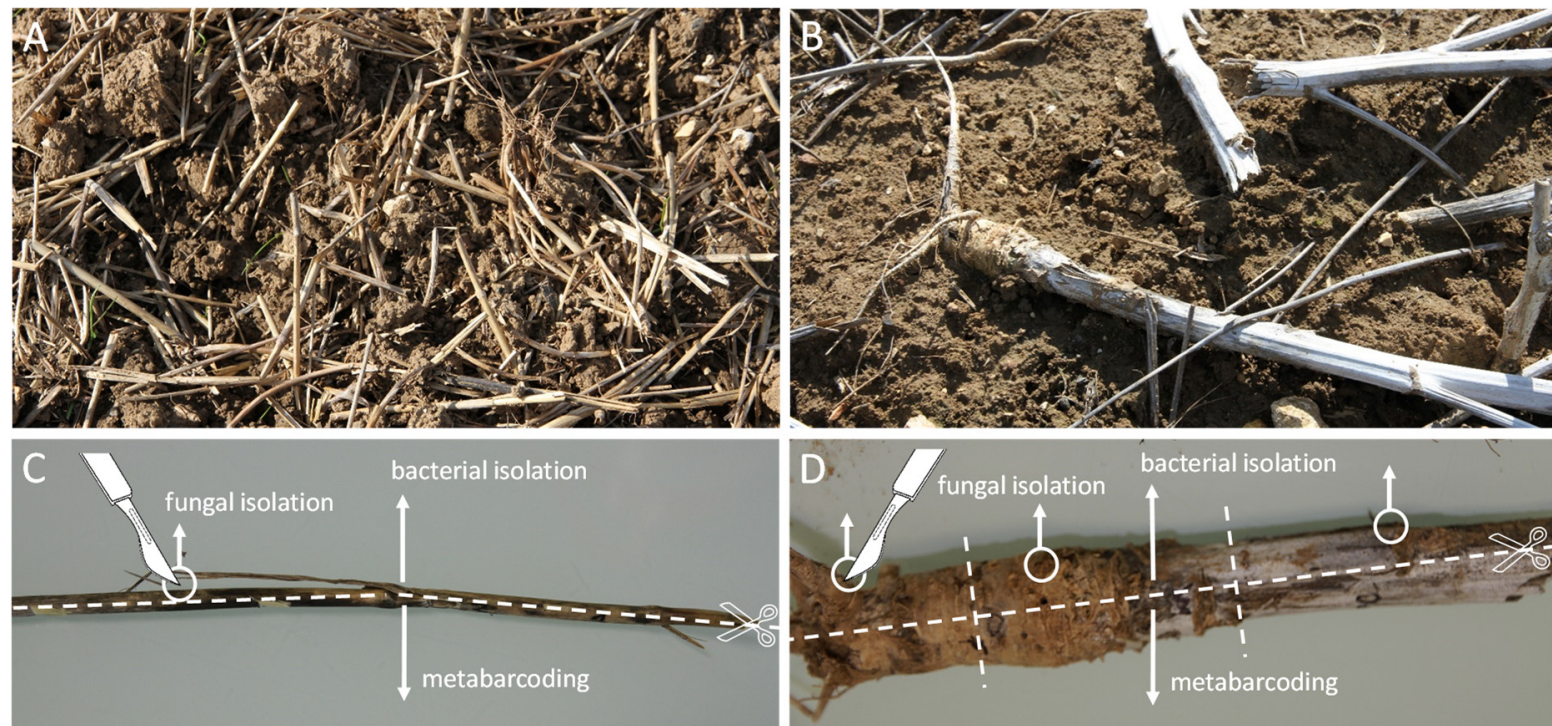

Figure 1. Sampling and preparation of crop residues. Wheat $(\mathbf{A})$ and oilseed rape residues $(\mathbf{B})$ on the ground in field plots. Wheat (C) and oilseed rape residues (D) cut lengthwise and selection of pieces of residue. For fungal isolation (total number of sample units $=1080$, see Figure 2), we used one $1 \mathrm{~mm}^{2}$ piece of residue cut from the first half section of each of $12 \mathrm{wheat}$ residues and $3 \times 1 \mathrm{~mm}^{2}$ pieces of residue cut from the first half section of each of four oilseed rape residues (one piece from the stem base, one from the start of the pivotal root, and one piece from the collar); for bacterial isolation (total number of sample units $=15$, see Figure 2), the rest of the first half section of residue was used for infusion. All the second half sections of the residues were used for metabarcoding [5]. 


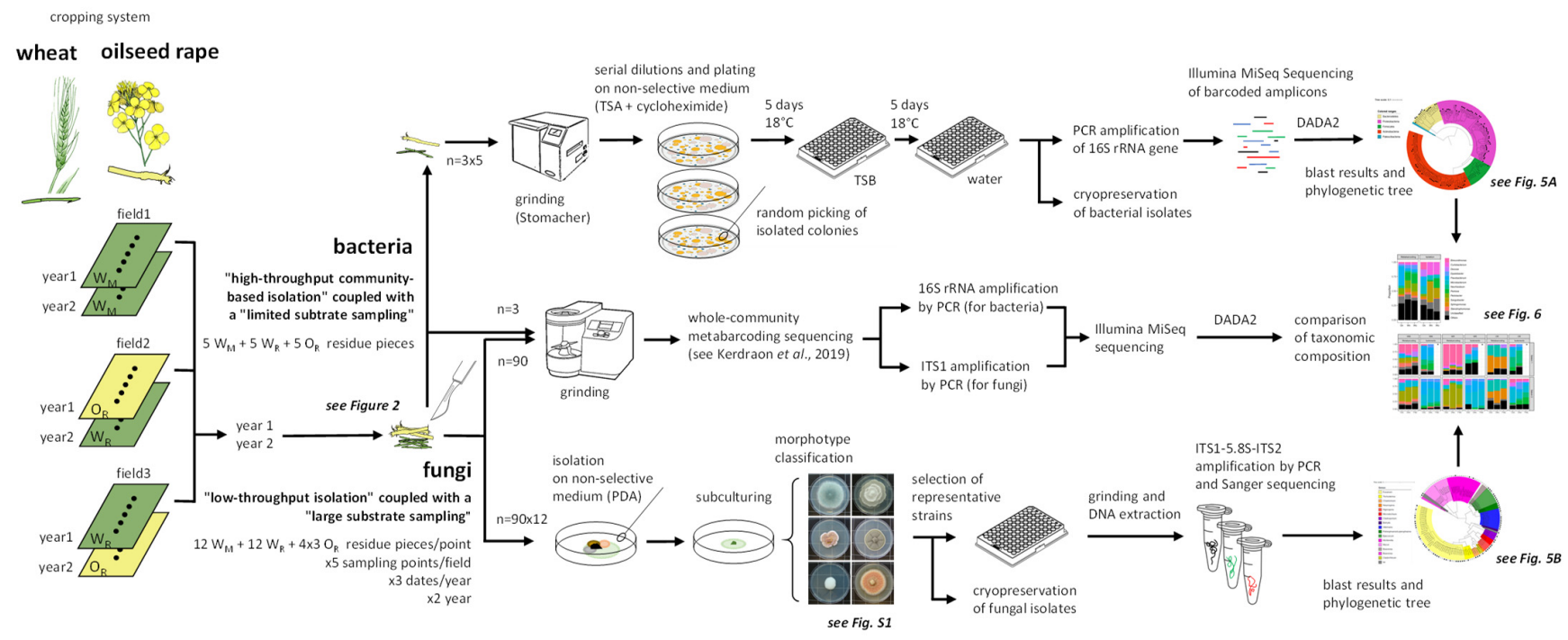

Figure 2. Overview of the culture-dependent molecular identification and whole-community metabarcoding strategies for characterizing and comparing the bacterial and fungal communities of wheat $(\mathrm{W})$ and oilseed rape $(\mathrm{O})$ residues.

\subsection{Culture-Dependent Molecular Identification of Residue-Associated Bacteria}

\subsubsection{Isolation of the Bacterial Fraction}

The pieces of residue $(5 \mathrm{~g})$ were soaked in $2 \mathrm{~mL}$ of phosphate-buffered saline (PBS, Sigma-Aldrich P4417) supplemented with Tween $20(0.05 \% v / v)$ per gram of fresh material. Residues were crushed and homogenized with a Stomacher blender (Mixwel, Alliance Bio Expertise) for two minutes. Serial dilutions of the resulting suspensions were plated on 1/10 strength tryptic soy agar (TSA; $17 \mathrm{~g} \cdot \mathrm{L}^{-1}$ tryptone, $3 \mathrm{~g} \cdot \mathrm{L}^{-1}$ soybean peptone, $2.5 \mathrm{~g} \cdot \mathrm{L}^{-1}$ glucose, $5 \mathrm{~g} \cdot \mathrm{L}^{-1} \mathrm{NaCl}, 5 \mathrm{~g} \cdot \mathrm{L}^{-1} \mathrm{~K}_{2} \mathrm{HPO}_{4}$, and $15 \mathrm{~g} \cdot \mathrm{L}^{-1}$ agar) supplemented with cycloheximide $\left(50 \mu \mathrm{g} \cdot \mathrm{mL}^{-1}\right)$. The plates were incubated for five days at $18{ }^{\circ} \mathrm{C}$, and 2232 colonies ( 1395 for $\mathrm{W}_{\mathrm{M}}, 744$ for $\mathrm{W}_{\mathrm{R}}$, and 93 for $\mathrm{O}_{\mathrm{R}}$ ) were picked (from two plates for each set of residue pieces) and subcultured in 96-well plates containing $200 \mu \mathrm{L}$ of tryptic soy broth (TSB) per well. One negative control (TSB with no added colony, as a control for sterility), one positive control (Agrobacterium tumefaciens CFBP 2413, control for growth and barcoding) and a water control (negative control for subsequent PCR assays) were included on all plates. The plates were incubated for five days at $18{ }^{\circ} \mathrm{C}$ with continual shaking $(70 \mathrm{rpm})$, and we then transferred $10 \mu \mathrm{L}$ of bacterial suspension to $90 \mu \mathrm{L}$ of sterile water for PCR amplification. We added $190 \mu \mathrm{L}$ of $80 \%$ glycerol to the remaining bacterial suspension in each well, which was then stored at $-80{ }^{\circ} \mathrm{C}$.

\subsubsection{High-Throughput Partial Sequencing of the $16 \mathrm{~S}$ rRNA Gene}

Molecular typing was performed on each bacterial isolate with the $515 \mathrm{f} / 806 \mathrm{r}$ primer pair (5'-GTGCCAGCMGCCGCGGTAA and 5'-GGACTACHVHHHTWTCTAAT [40]) targeting the $\mathrm{v} 4$ region of $16 \mathrm{~S}$ rRNA gene, according to the procedure described by Armanhi et al. [25]. Briefly, each primer was labeled with a unique plate barcode. PCR amplification was performed in $25 \mu \mathrm{L}$ reaction mixtures containing $2.5 \mu \mathrm{L}$ boiled bacterial suspension $\left(99^{\circ} \mathrm{C}, 5 \mathrm{~min}\right.$ ), $0.25 \mu \mathrm{L}$ GoTaq flexi DNA Polymerase (Promega), $5 \mu \mathrm{L}$ Greenflexi buffer (Promega), $2 \mu \mathrm{L}$ dNTP (Promega U151B, $2.5 \mathrm{mM}$ ), $1.5 \mu \mathrm{L} \mathrm{MgCl}_{2}(25 \mathrm{mM}$ ), $0.5 \mu \mathrm{L}$ of each primer $(10 \mathrm{mM})$ and $12.75 \mu \mathrm{L}$ water. The following conditions were used for amplification: 35 cycles of amplification at $94{ }^{\circ} \mathrm{C}(30 \mathrm{~s}), 50{ }^{\circ} \mathrm{C}(45 \mathrm{~s})$ and $68^{\circ} \mathrm{C}(90 \mathrm{~s})$, followed by a final elongation at $68^{\circ} \mathrm{C}$ for $10 \mathrm{~min}$. Amplicons were purified with magnetic beads (Sera-Mag ${ }^{\mathrm{TM}}$, Merck) at a beads-to-PCR product ratio of 1.2. Amplicons with plate barcodes from this first PCR were pooled on a single plate and a second PCR amplification was performed to incorporate Illumina adapters and unique well barcodes. PCR was performed with $10 \mu \mathrm{L}$ Greenflexi buffer, $2 \mu \mathrm{L}$ dNTP, $4 \mu \mathrm{L} \mathrm{MgCl}_{2}, 0.2 \mu \mathrm{L}$ GoTaq flexi DNA 
polymerase, $26.8 \mu \mathrm{L}$ water, $2 \mu \mathrm{L}$ of each primer, and $5 \mu \mathrm{L}$ purified PCR1 product. PCR conditions were as follows: initial denaturation at $94^{\circ} \mathrm{C}(1 \mathrm{~min})$, followed by 12 cycles of $94{ }^{\circ} \mathrm{C}(1 \mathrm{~min}), 55^{\circ} \mathrm{C}(1 \mathrm{~min})$ and $68^{\circ} \mathrm{C}(1 \mathrm{~min})$, and a final elongation at $68^{\circ} \mathrm{C}$ for $10 \mathrm{~min}$. PCR products were purified with Sera-Mag ${ }^{\mathrm{TM}}$, pooled in a single tube with $10 \%$ PhiX and sequenced with MiSeq reagent kit v2 (500 cycles).

\subsubsection{Sequence Analyses}

Fastq files were demultiplexed and plate-specific primers were trimmed with cutadapt version 1.8 [41]. Fastq files were processed with DADA2 1.6.0 [42], using the following parameters: truncLen $=c(180,120), \operatorname{maxN}=0, \operatorname{maxEE}=c(1,1)$, truncQ $=5$. Chimeric sequences were identified and removed with the removeBimeraDenovo function of DADA2. The taxonomic affiliations of amplicon sequence variants (ASVs) were determined with a naive Bayesian classifier [43] implemented in DADA2. ASVs derived from the 16S rRNA gene were classified with the Silva 132 taxonomic training data (silva_nr_v132_train_set.fa.gz). ASVs that were taxonomically assigned to eukaryotic, mitochondrial of chloroplast sequences, as well as ASVs unclassified at phylum rank, were removed. Sequence contaminants (i.e., detection of DNA associated to extraction kits and PCR reagents) were identified with decontam package version 1.4 [44], using the "prevalence" method at a threshold of 0.01. Finally, ASVs were filtered on the basis of their relative abundances per well. Only ASVs with a relative abundance greater than $1 \%$ per well were retained. A neighbor-joining phylogenetic tree was built with the phangorn R package v 2.5 .5 [45], using a multiple sequence alignment obtained with the DECIPHER R package v. 2.12.0 [46].

\subsection{Culture-Dependent Molecular Identification of Residue-Associated Fungi}

\subsubsection{Isolation of the Fungal Fraction}

Each piece of residue was deposited on a PDA (potato dextrose agar, $39 \mathrm{~g} \cdot \mathrm{L}^{-1}$ ) plate and kept at $18^{\circ} \mathrm{C}$ in the dark for 5-8 days. Dominant and non-dominant strains were purified by successive subcultures on PDA. Only one fungal morphotype was chosen per sample, with the aim of collecting 20 to 25 strains per sampling point $\times$ period combination $\times$ plot. A total of 424 fungal strains were isolated and kept at $-80{ }^{\circ} \mathrm{C}$ in glycerol-water solution $(20 \% v / v)$ for long-term storage.

\subsubsection{Molecular Characterization of the Fungal Collection by Sanger Sequencing}

The strains stored at $-80^{\circ} \mathrm{C}$ were subcultured on PDA plates. The mycelium of each plate was scraped off and placed in the well of a 96-well plate. The mycelia were then lyophilized and ground with a tungsten bead in $50 \mu \mathrm{L}$ lysis buffer (Qiagen DNeasy-Plant AP1 buffer) with a Retsch ${ }^{\mathrm{TM}}-\mathrm{MM} 400$ (Retsch, France) mill operating at $20 \mathrm{~Hz}$ for $30 \mathrm{~s}$. The DNA was extracted with the DNeasy Plant Mini DNA extraction kit (Qiagen, France), according to the simplified instructions provided by the manufacturer, as the DNA columns were not used. The DNA of all strains was quantified with a NanoDrop ND-1000 UV-Vis spectrophotometer (NanoDrop, Wilmington, DE, USA), adjusted to 10 to $20 \mathrm{ng} \cdot \mathrm{mL}^{-1}$ and stored at $-20^{\circ} \mathrm{C}$ until use. For molecular characterization, a fragment encompassing the ITS regions (ITS1 and ITS2) and the small 5.8S subunit of rDNA was amplified from each DNA with the ITS1F [47] and ITS4 [48] primers. The PCR mixture contained $1 \times$ master mix for the Type-it Microsatellite PCR Kit (Qiagen, France), $3 \mu \mathrm{L}$ of Q-Solution and $0.25 \mu \mathrm{M}$ of each primer in a total volume of $30 \mu \mathrm{L}$. PCR was performed with an Applied Biosystems 9700 thermal cycler. The amplification parameters were as follows: initial denaturation at $95{ }^{\circ} \mathrm{C}$ for $5 \mathrm{~min}, 35$ cycles of $95^{\circ} \mathrm{C}$ for $60 \mathrm{~s}, 60{ }^{\circ} \mathrm{C}$ for $30 \mathrm{~s}$, and $72{ }^{\circ} \mathrm{C}$ for $60 \mathrm{~s}$, and a final elongation at $72{ }^{\circ} \mathrm{C}$ for $10 \mathrm{~min}$. We checked the quality of the PCR products by electrophoresis in $2 \%$ agarose gels. The PCR products were then subjected to single-strand sequencing by the Sanger method (Eurofins, France). Chromatograms were checked with DNASTAR lasergene sequence analysis software [49] to generate the sequences used for molecular identification. The taxonomic assignment of each sequence was performed with a naïve Bayes classifier on the UNITE7.1 database. 


\subsubsection{Phylogenetic Tree for the ITS Region of Fungal Strains}

The ITS sequences of each of the 424 fungal strains were blasted against each other to prevent redundancy in subsequent analyses. We obtained 131 unique sequences, which were considered to be 'representative ASVs' of the fungal collection. A phylogenetic tree of these ASVs was built with the "build" function of ETE3 v3.1.1 [50], as implemented on GenomeNet (https:/ / www.genome.jp/tools/ete/, accessed on 22 July 2021). An alignment was generated with MAFFT v6.861b, using the default options [51]. The tree was constructed with FastTree v2.1.8, using the default parameters [52]. The values at the nodes were SH-like local support. Data were visualized with Interactive Tree Of Life (iTOL) v4 [53].

\section{Results}

\subsection{Bacterial Culture Collection}

The analysis of the cultivable bacterial fraction, based on 2201 colonies for which sequencing was successful, led to a median of 3709 reads per well ( $\min 27$, max 18774; Figure S1A) and to the detection of $753 \mathrm{ASVs}$ (min 1 per well, max 19 per well, median.2 per well). The high number of ASVs in each well often resulted from the presence of sequences presenting only one single nucleotide polymorphisms (SNPs). For instance, two ASVs were systematically detected in the wells corresponding the positive PCR control (A. tumefaciens CFBP 2413). However, these two ASVs had different relative abundances. The highly abundant ASV ( $>95 \%$ of the reads) was $100 \%$ identical to the genomic sequence of $A$. tumefaciens CFBP 2413 , and the lower abundance ASV ( $<5 \%$ reads) presented one SNP relative to the genomic sequence of A. tumefaciens CFBP 2413. Multiple ASVs detected within a well thus probably reflect amplification and/or sequencing artifacts. We corrected for these errors by applying a conservative filter to the read set retained, in which we retained only ASVs with a relative abundance exceeding $5 \%$ in the well concerned. This filtering procedure reduced the number of ASVs to 158, with a median of one ASV per well (1-5 ASVs; Figure S1B). These 158 ASVs were affiliated to five phyla (Actinobacteria, Bacteroidetes, Firmicutes, Patescibacteria, and Proteobacteria) and 36 bacterial genera (Figure S1D and Table S1). The most prevalent bacterial strains recovered with the culture-dependent approach were related to Sanguibacter $(n=677)$ and Curtobacterium $(n=519)$, two genera from Actinobacteria (Figure S1C).

\subsection{Comparison of Bacterial Culture-Collection and Metabarcoding Data}

The metabarcoding analysis of the same samples ( 3 sets $\times 5$ residue pieces), performed by Kerdraon et al. [5], identified 1129 ASVs corresponding to 16 phyla and 231 bacterial genera. The most prevalent ASVs were affiliated to the phyla Actinobacteria, Bacteroidetes, and Proteobacteria (Figure S2A) and the genera Sphingomonas and Neorhizobium (Figure S2B). Of the 158 cultured ASVs, a total of 89 were identical to ASVs present in metabarcoding libraries (Figure $3 \mathrm{~A}$ and Table S1). The most abundant taxa identified by metabarcoding were successfully isolated and eight of them were representative strains in the community-based culture collection (Figure S2B). Most of the collected strains not previously detected by metabarcoding belonged to Firmicutes or Actinobacteria (Figure 3A). The culture collection was particularly enriched in members of the families Microbacteriaceae and Paenibacillaceae (Table S1). Comparison of the profiles consisting of the 12 most abundant bacterial taxonomic groups highlighted that ASVs affiliated to Actinobacteria (Microbacterium, Curtobacterium, and Sanguibacter) were more frequently represented in the culture-dependent molecular identification data than in the metabarcoding data (Figure 4A). Conversely, ASVs affiliated to the genera Dyadobacter, Pedobacter, and Flavobacteria were more frequently represented in the metabarcoding data. It is worth noting that the differences in bacterial profiles between wheat $\left(W_{M}\right.$ and $\left.W_{R}\right)$ and oilseed rape $\left(O_{R}\right)$ residues highlighted by metabarcoding [5] also appeared by isolation (e.g., prevalence of Flavobacterium, Devosia, and Curtobacterium; Figure 4A). 


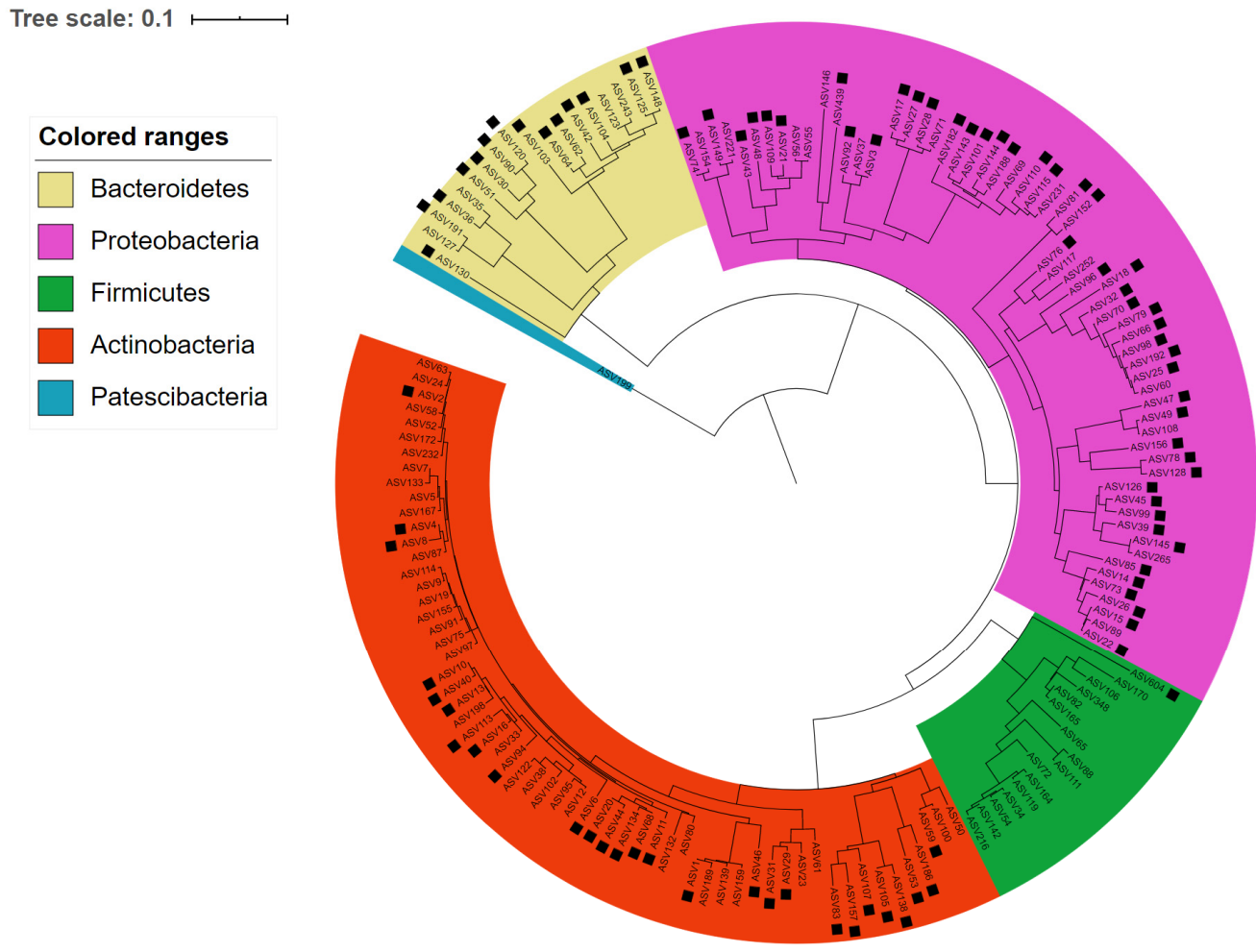

(A)
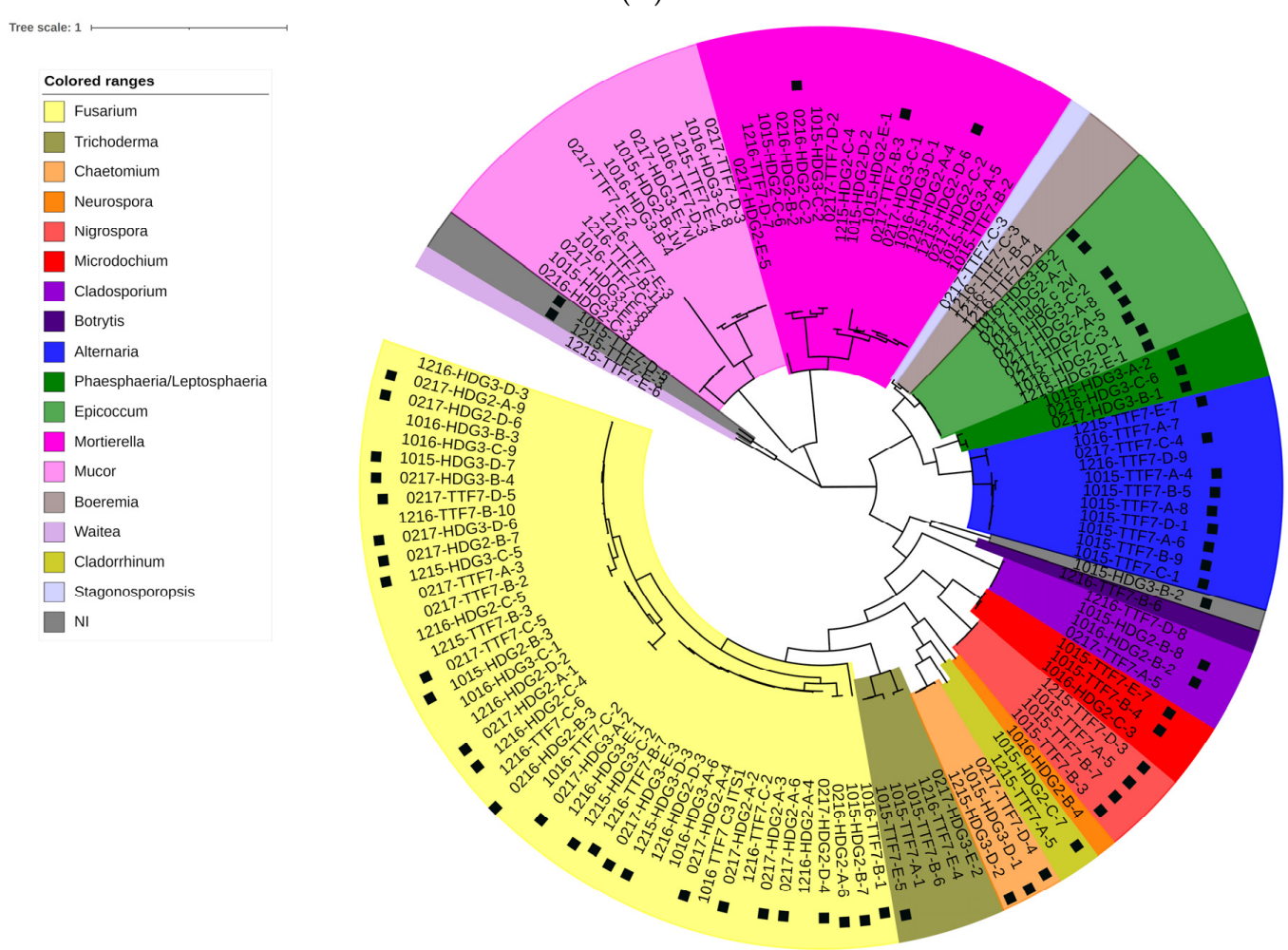

(B)

Figure 3. Phylogenetic distribution of the bacterial strains (from 15 residue samples) and fungal strains (from 1080 residue samples) recovered through culture collection. A neighbor-joining phylogenetic tree was constructed (A) with the v4 region of 16S rRNA gene of all unique bacterial ASVs $(n=158)$ and (B) the ITS1-5.8S-ITS2 region of all unique fungal ASVs $(n=131)$ detected in each culture collection. The presence of an ASV from isolated strain displaying $100 \%$ identity to the corresponding region in the metabarcoding dataset [5] is indicated by a black square. 


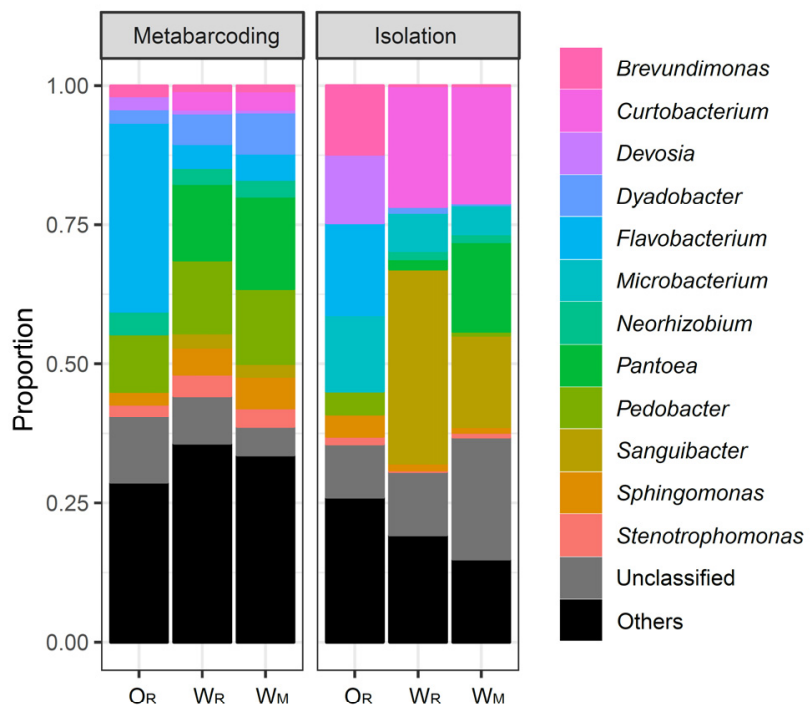

(A)
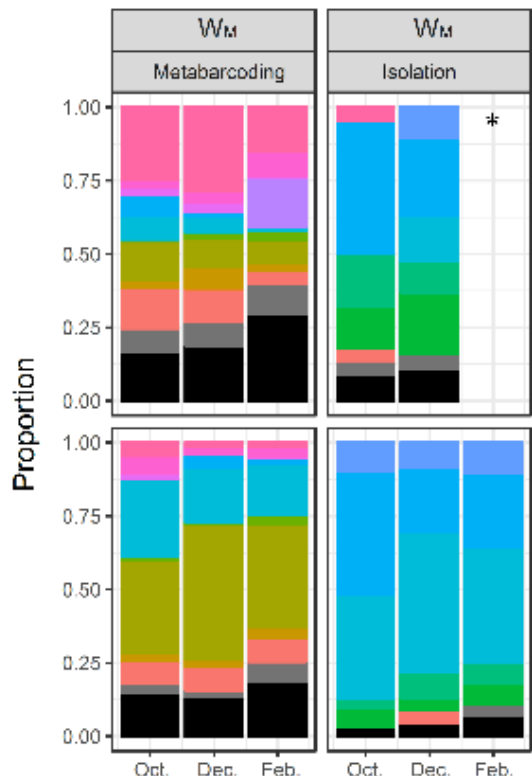

Oct Dec Feb.
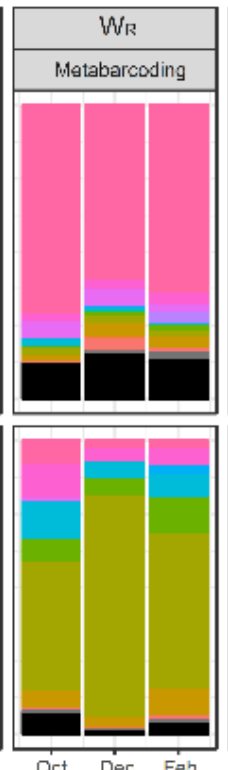

Dct. Dec. Feb.

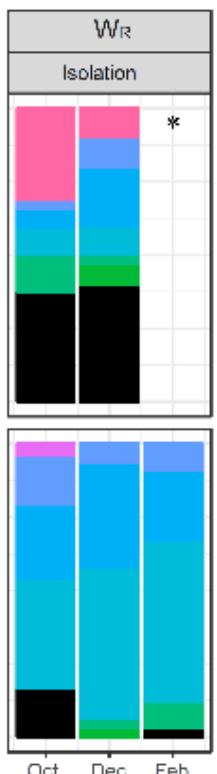

(B)

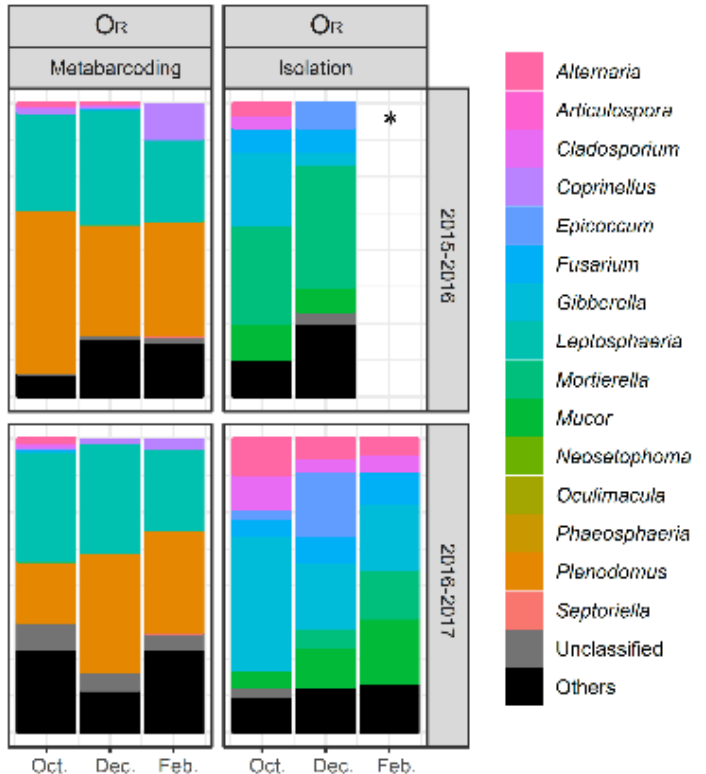

Oct. Decc. Febt. Articulesporar Coprinelius Epicorcum Fisarilin Gibbcrcila Morijerella Mucor Neoselophoma Phoeosphaeria Plenodomus Septoriefia Unclassified Oct. Dec. Feb.

$$
\text { . }
$$

Figure 4. Profiles of the residue-associated bacterial and fungal communities obtained by metabarcode sequencing ('metabarcoding') and by culture-dependent molecular identification ('isolation'). (A) For the bacterial community, comparisons were based on the same $3 \times 5$ wheat $(\mathrm{W})$ and oilseed rape $(\mathrm{O})$ residue samples collected from the wheat monoculture plot $\left(\mathrm{W}_{\mathrm{M}}\right)$ and the two wheat-oilseed rape rotation plots $\left(W_{R}\right.$ and $\left.O_{R}\right)$ in October 2015. (B) For the fungal community, comparisons were based on the same $90 \times 12$ wheat $(\mathrm{W})$ and oilseed rape $(\mathrm{O})$ residue samples collected from the wheat monoculture plot $\left(W_{M}\right)$ and the two wheat-oilseed rape rotation plots $\left(W_{R}\right.$ and $\left.O_{R}\right)$ during three sampling periods (October, December, and February) in the 2015-2016 and 2016-2017 cropping seasons. Only the 12 most abundant bacterial genera and the 16 most abundant fungal genera are presented. The composition of the three sets marked by * is missing due to unsuccessful isolation. 


\subsection{Fungal Culture Collection}

The analysis of the cultivable fungal fraction led to the isolation and sequencing of 424 fungal strains. Morphotypes were described from photographs for 171 of these strains (Figure S3) and full ITS regions (ITS1-5.8S-ITS2) were sequenced to assess the taxonomic diversity of the collection (Table S2). A dataset of 131 unique ASVs was obtained by blasting the 424 sequences against each other. The 131 ASVs were affiliated to 17 genera, with some left unclassified (Table S2, Figure 3B). The most prevalent strains isolated were affiliated to the genus Fusarium.

\subsection{Comparison of Fungal Culture Collection and Metabarcoding Data}

The metabarcoding analysis of the corresponding samples (90 sets $\times 12$ pieces), presented in Kerdraon et al. [5], identified 894 ASVs belonging to 148 fungal genera. As for bacteria, the differences in fungal profiles between wheat $\left(W_{M}\right.$ and $\left.W_{R}\right)$ and oilseed rape $\left(\mathrm{O}_{\mathrm{R}}\right)$ residues, and between the two cropping seasons highlighted by metabarcoding [5], also appeared by isolation (Figure 4B). The ASVs corresponding to the most frequently isolated fungal genera were also detected by metabarcoding, except the ASVs affiliated to the genera Mucor and Mortierella, represented by 34 and 46 strains, respectively (Table S3). Strains from some other genera, such as Actinomucor, Boeremia, Botrytis, Neurospora, and Stagonosporopsis, were isolated at a very low frequency and were not detected at all by metabarcoding. Several other genera, such as Epicoccum and Fusarium were overrepresented in analyses based on isolation relative to those based on metabarcoding, particularly for wheat residues $\left(W_{M}\right.$ and $\left.W_{R}\right)$ during the second cropping season (2016-2017) (Figure 4). Conversely, the ASVs affiliated to several of the most frequent fungal genera identified by metabarcoding were obtained rarely, if at all, by isolation. This was the case for Leptosphaeria and Plenodomus (probably L. maculans and P. biglobosus, known to be pathogens of oilseed rape [35]) in $\mathrm{O}_{\mathrm{R}}$ and Oculimacula (probably O. yallundae, known to be pathogen of wheat that survives on straw [54]) in $W_{M}$ and $W_{R}$.

For technical reasons, the comparison of the results obtained by the two approaches was less straightforward than for bacteria. Indeed, the size of the genomic region amplified and sequenced for fungal strain identification in the culture-dependent approach (ITS1-5.8S-ITS2 region) was larger and included the genomic region targeted in the cultureindependent approach (ITS1 region only). Thus, the ITS1 region of one ASV obtained by metabarcoding could potentially display $100 \%$ identity with the IST1 of the sequenced ITS1-5.8S-ITS2 region of several isolated strains. Overall, 33 of the 894 ASVs identified by metabarcoding were $100 \%$ identical to one or several ASVs from the dataset of the collection (Figure 3B). As an example of equivocal matches, one ASV detected by metabarcoding displayed 100\% identity to eight ASVs of the genus Epicoccum from the collection. Conversely, several ASVs detected by metabarcoding identified displayed 100\% identity to one ASV from one genus (e.g., Alternaria and Fusarium).

\section{Discussion}

\subsection{Complementarity of the Two Approaches}

Our main objective was to assess the cultivability of the most abundant taxa in the crop residue microbiome, using two different isolation strategies adapted to the differential distributions of bacterial and fungal diversity. The strategy developed to ensure that a maximum of fungal diversity was covered involved broad sampling effort $(n=1080)$ coupled with a low-throughput isolation. By contrast, this developed to ensure maximum coverage of bacterial diversity involved a very low sampling effort $(n=15)$ coupled with a high-throughput isolation. The diversity obtained with metabarcoding data in Kerdraon et al. [5] — same order of magnitude for bacteria, i.e., 1129 ASVs for 231 genera (on the corresponding 15 residue pieces) than for fungi 894 ASVs for 148 genera (on the 1080 residue pieces) — showed that this strategy made sense. As expected, the actual diversity found by isolation did not allow us to characterize the microbiome as precisely, but the bacterial diversity (158 ASVs for 36 genera) was also of the same order of magnitude 
than the fungal diversity (131 ASVs for 17 genera), probably limited by competition phenomena in each non-selective culture medium. Our objective was not to characterize the overall microbiome as precisely as by metabarcoding, nor to compare microbial community on wheat and oilseed rape residue (for that, see extensive comparison of alpha and beta diversity in Kerdraon et al. [5]). Our objective was to assess the cultivability of the most abundant taxa in the crop residue microbiome, and the chosen strategy was effective for this. We managed to identify several of the most common ASVs revealed by metabarcoding, but also ASVs specific to each approach.

\subsubsection{The Two Approaches Yield Consistent Results, Particularly for Bacteria}

The isolation strategy employed for bacteria yielded a community profile comparable to that obtained with the metabarcoding approach. Bacterial ASV appeared less diverse with the culture-dependent approach, but most of the dominant ASVs were recovered on a single synthetic medium. Thus, differences between metabarcoding and isolation were reflected in sampling depth, with some rare taxa difficult to isolate by culture. The use of a single synthetic medium in a single set of growing conditions was sufficient for isolation of the most abundant taxa of the residue microbiota. For example, some abundant taxa affiliated to Massilia and Flavobacteria were not recovered, probably due to the dilution of TSA $(1 / 10)[55,56]$. However, one strain from the recently identified superphylum Patescibacteria [57], the members of which are not easy to isolate in pure culture [12], was successfully obtained. About $40 \%$ of the bacterial strains obtained by culture methods were not detected with the metabarcoding. Interestingly, most of these strains belonged to Actinobacteria and Firmicutes. The reasons for the underestimation of the presence of these bacterial phyla within the residue microbiome by the culture-independent approach remain unclear. Biases introduced during DNA extraction procedures for endospore-forming Firmicutes may be responsible [58]. However, other parameters must also underlie these differences, as the family of Actinobacteria underestimated in our study (Microbacteriaceae) does not form spores [59], and some spore-forming Firmicutes were detected by metabarcoding, but not in culture-dependent approaches.

\subsubsection{The Two Approaches Provide Complementary Information, Particularly for Fungi}

The strategy combining broad sampling effort with low-throughput isolation revealed general differences between the fungal profiles obtained this way and by metabarcoding. With the exception of Alternaria, some of the most abundant fungal taxa in metabarcoding were absent with isolation. This was the case for Lesptosphaeria (L. maculans), Plenodomus (P. biglobosus), and Oculimacula (O. yallundae), all of which are known to be pathogenic. However, a very large number of strains from different genera were frequently isolated (e.g., Fusarium, Epicoccum, Boeremia, Botrytis, Mortierella, and Mucor, known to be highly competitive in vitro due to their high growth rates relative to other fungi), despite their low proportions in metabarcoding. The isolation medium is known to affect the growth rates of fungal species and induce selective effects, potentially accounting for differences between the two approaches. However, the differences in growth rate between taxa cannot necessarily be diminished through the use of different growth conditions. L. maculans and Z. tritici are two good examples: these two pathogenic species are widely found on oilseed rape and wheat residues, respectively, and are widely cultivable, but were never isolated in this study, probably due to competition with fast-growing species, such as Fusarium sp., many of which originate from the soil and colonize the surface of the residues. As for bacteria, the other reasons for the underrepresentation of some fungal phyla in the culture-independent approach remain unclear. The reasons could be methodological: (i) the sampling strategy, with possible differences in the spatial distribution of microbial diversity, although pieces of residue analyzed by culture-dependent and culture-independent approaches came from the same samples (see Figure 1); (ii) the genomic regions sequenced and analyzed, with possible differences between metabarcoding and single-strain barcoding (see below). Yang et al. [6] characterized the fungal endophytic diversity in field-grown soybean roots by combining 
culture-dependent and culture-independent approaches. They isolated several fungal root endophytes that were not detected by metabarcoding but could not explain it. Moreover, by conducting pathogenicity assays they found, surprisingly, that the most frequently isolated fungal pathogens did not cause disease in soybean. This result suggests that the reason for the underrepresentation (or the absence) of certain taxa might be also 'biological'. There would be significant benefit to identifying and studying this reason.

Metabarcoding is, thus, not sufficient in itself, and isolation definitely provides added value for the accurate characterization of the fungal community in residues. Moreover, three ASVs from three strains from the culture collection matched three unidentified ASVs with $100 \%$ identity. The strains were not identified due to a lack of identity with sequences in databases, but it would be possible to characterize them phenotypically, by enzyme profiling or pathotyping, to obtain additional information about the residue-associated fungal community.

\subsection{Some Methodological Considerations}

In general, amplicon-based metagenomic approaches are based on small fragments, whereas the molecular identification of single strains can be based on longer barcodes and Sanger sequencing [60]. This is one of the limitations of our comparison between culturedependent and culture-independent approaches. Indeed, we found that an ASV obtained by metabarcoding could display $100 \%$ sequence identity to several cultured strains. In metabarcoding, only the ITS1 part was used for identification, whereas, in single-strain barcoding, the entire ITS1-5.8S-ITS2 region was sequenced. Intraspecies polymorphism may be hidden (e.g., 100\% identity of an ASV detected by metabarcoding to eight ASVs from the genus Epicoccum). Therefore, the culture-independent approach is likely to underestimate taxonomic and functional fungal diversity. Some studies (e.g., [61,62]) have suggested using long-read sequencing techniques for metabarcoding to improve taxonomic resolution, thereby providing a more accurate perception of the functional diversity of the residue microbial community. Indeed, although the ITS region generally performs well as a fungal barcoding marker, it is less efficient for some genera, and it may be necessary to sequence several genes to identify a strain correctly [63]. Even in this case, taxonomic identification is dependent on the presence of the corresponding sequences in international databases. For bacteria, the v4 region of $16 \mathrm{~S}$ rRNA gene has poor discriminatory power at species level [64] and another more resolutive gene could be used as a portion of gyrB, a gene encoding the $\beta$ subunit of the DNA gyrase [65].

In this study, we used only one culture medium. This limited the scope of our results, particularly with regard to what could be conducted on other substrates by 'culturomics', i.e., high-throughput approaches based on multiple growth conditions (several media, selective or not, aerobic, anaerobic, or micro-aerophilic, at different temperatures, and over different time steps). However, we showed that a single medium was sufficient to isolate not only most of the most abundant bacterial taxa identified by metabarcoding, but also some ASVs not retrieved by the culture-independent approach. In the future, the analysis of the fungal community would benefit from being conducted using a mineral medium to capture a greater biodiversity, especially for antagonistic fungi.

It appears to be essential to combine the two approaches if we wish to go beyond descriptive aspects and characterize the ecological function of a microbial community. Results that support this view were obtained on the root microbiota in natural populations of Arabidopsis thaliana [20]: several of the most abundant fungal taxa associated with the roots were retrieved as pure cultures, thus providing opportunities for the reconstitution of the root microbiota-mono- but also multi-kingdom synthetic microbial consortia-under laboratory conditions. This purpose is particularly relevant to identify potential biocontrol agents. Indeed, several taxa that we identified in this study are described in the literature for their antagonistic properties against plant pathogens (e.g., the ability of certain yeast taxa to multiply rapidly and produce antibiotics, indicating the potential to exploit them against soil-borne diseases [66]). The main advantage of microbial isolation is that the different 
strains from a specific ecosystem can be preserved and then tested in the same ecological niche - individually or after the creation of synthetic communities [36,67] - to decipher their ecological functions and identify all the positive specific interactions $[20,68,69]$. Conversely, metabarcoding limits the biases linked to the cultivable/non-cultivable nature of microbes in the fine characterization of communities.

\section{Conclusions}

The cultivable fraction of the fungal and bacterial communities of crop residues appeared to be neither as low as the " $1 \%$ paradigm" long associated with the rhizosphere microflora and recently questioned [70,71], nor as high as the 50\% sometimes reported for the phyllosphere microflora [16,72]. We focused on the cultivable fraction of the most abundant taxa, which appeared intermediate between those for soil and living plants. This view is consistent with residues acting as an 'ecotone' at the interface between the soil and the phyllosphere [2]. By focusing here on culture-dependent aspects, we have extended a broader experimental work $[2,34,35]$ and paved the way for further improvements for studying the microbiome of arable crop residues. The two approaches-isolation and metabarcoding-were confirmed to be complementary for the 'residue sphere' as shown for other ecosystems, and their combination provided a more complete description of the microbiological diversity of residues. Taking into account the microbiome of crop residues is essential, not only to improve the quantitative management of these residues as source of plant pathogens, especially Z. tritici (in wheat) and L. maculans (in oilseed rape), but also to characterize potential biocontrol agents-individual strains or synthetic communities-against them.

Supplementary Materials: The following are available online at https:/ / www.mdpi.com/article/10.3 390/d13090404/s1, Figure S1: Community-based culture collection of bacterial strains isolated from three wheat and oilseed rape residue samples, Figure S2: Analysis of the bacterial diversity of three wheat and oilseed rape residue samples characterized by metabarcoding, Figure S3: Photographs of 171 fungal morphotypes representative of the 424 fungal taxa, Table S1: Bacterial strains isolated from three sets of residues, Table S2: Fungal strains isolated from pieces of residue, Table S3: Genera of fungal strains isolated and identified $(n=424)$ from 1080 pieces of wheat $(W)$ and oilseed rape $(O)$ residue.

Author Contributions: Conceptualization, V.L., L.K., M.B., M.-H.B. and F.S.; Methodology, V.L, L.K., M.B., A.-L.L., C.M., B.B. and F.S.; Data Analysis, V.L., L.K., M.B., A.-L.L., C.M. and F.S.; WritingOriginal Draft Preparation, V.L., L.K. and F.S.; Writing-Review and Editing, V.L., L.K., M.B., M.-H.B., M.F.-L.S. and F.S.; and Supervision and Project Administration, V.L. and F.S. All authors have read and agreed to the published version of the manuscript.

Funding: This study was supported by a grant from the European Union Horizon Framework 2020 Program (EMPHASIS program, agreement no. 634179) covering the 2015-2019 period, and was performed in collaboration with the GeT core facility, Toulouse, France (http://get.genotoul.fr/, accessed on 22 July 2021), supported by France Génomique National Infrastructure, funded as part of the Investissement d'avenir program managed by Agence Nationale pour la Recherche (contract ANR10-INBS-09). BIOGER benefits from the support of Saclay Plant Sciences-SPS supported by Agence Nationale pour la Recherche (contract ANR-17-EUR-0007).

Institutional Review Board Statement: Not applicable.

Informed Consent Statement: Not applicable.

Data Availability Statement: Data from isolation and single-strain barcoding is presented in Supplementary Material. Data from metabarcoding is available is available from the European Nucleotide Archive (ENA) under the study accession PRJEB27255 (sample SAMEA4723701 to SAMEA4724326).

Acknowledgments: We thank Julie Sappa for her help correcting our English.

Conflicts of Interest: The authors declare no conflict of interest. 


\section{References}

1. Smil, V. Crop residues: Agriculture's largest harvest crop residues incorporate more than half of the world's agricultural phytomass. BioScience 1999, 49, 299-308. [CrossRef]

2. Kerdraon, L.; Laval, V.; Suffert, F. Microbiomes and pathogen survival in crop residues, an ecotone between plant and soil. Phytobiomes J. 2019, 3, 246-255. [CrossRef]

3. Pascault, N.; Cécillon, L.; Mathieu, O.; Hénault, C.; Sarr, A.; Lévêque, J.; Farcy, P.; Ranjard, L.; Maron, P.-A. In situ dynamics of microbial communities during decomposition of wheat, rape, and alfalfa residues. Microb. Ecol. 2010, 60, 816-828. [CrossRef] [PubMed]

4. Cobo-Díaz, J.F.; Baroncelli, R.; Le Floch, G.; Picot, A. Combined metabarcoding and co-occurrence network analysis to profile the bacterial, fungal and Fusarium communities and their interactions in maize stalks. Front. Microbiol. 2019, 10, 261. [CrossRef]

5. Kerdraon, L.; Balesdent, M.-H.; Barret, M.; Laval, V.; Suffert, F. Crop residues in wheat-oilseed rape rotation system: A pivotal, shifting platform for microbial meetings. Microb. Ecol. 2019, 77, 931-945. [CrossRef]

6. Yang, H.; Ye, W.; Ma, J.; Zeng, D.; Rong, Z.; Xu, M.; Wang, Y.; Zhen, X. Endophytic fungal communities associated with field-grown soybean roots and seeds in the Huang-Huai region of China. PeerJ 2018, 6, e4713. [CrossRef]

7. Øvreås, L.; Torsvik, V. Microbial diversity and community structure in two different agricultural soil communities. Microb. Ecol. 1998, 36, 303-315. [CrossRef]

8. Fath, B.D.; Scharler, U.M.; Ulanowicz, R.E.; Hannone, B. Ecological network analysis: Network construction. Ecol. Model. 2007, 208, 49-55. [CrossRef]

9. Daniel, R. The soil metagenome-A rich resource for the discovery of novel natural products. Curr. Opin. Biotechnol. 2004, 15, 199-204. [CrossRef] [PubMed]

10. Comby, M.; Gacoin, M.; Robineau, M.; Rabenoelina, F.; Ptas, S.; Dupont, J.; Profizi, C.; Baillieul, F. Screening of wheat endophytes as biological control agents against Fusarium head blight using two different In Vitro tests. Microbiol. Res. 2017, 202, 11-20. [CrossRef]

11. Tuan Hamzah, T.N.; Lee, S.H.; Hidayat, A.; Terhem, R.; Faridah-Hanum, I.; Mohamed, R. Diversity and characterization of endophytic fungi isolated from the tropical mangrove species, Rhizophora mucronata, and identification of potential antagonists against the soil-borne fungus, Fusarium solani. Front. Microbiol. 2018, 25, 1707. [CrossRef] [PubMed]

12. Lewis, W.H.; Tahon, G.; Geesink, P.; Sousa, D.Z.; Ettema, T.J.G. Innovations to culturing the uncultured microbial majority. Nat. Rev. Microbiol. 2020. [CrossRef] [PubMed]

13. Wintzingerode, F.V.; Göbel, U.B.; Stackebrandt, E. Determination of microbial diversity in environmental samples: Pitfalls of PCR-based rRNA analysis. FEMS Microbiol. Rev. 1997, 21, 213-229. [CrossRef]

14. Armanhi, J.S.L.; de Souza, R.S.C.; de Brito Damasceno, N.; de Araújo, L.M.; Imperial, J.; Arruda, P. A community-based culture collection for targeting novel plant growth-promoting bacteria from the sugarcane microbiome. Front. Plant Sci. 2018, 8, 2191. [CrossRef]

15. Müller, T.; Ruppel, S. Progress in cultivation-independent phyllosphere microbiology. FEMS Microbiol. Ecol. 2014, 87, 2-17. [CrossRef]

16. Ritz, K. The Plate Debate: Cultivable communities have no utility in contemporary environmental microbial ecology. FEMS Microbiol. Ecol. 2007, 60, 358-362. [CrossRef]

17. Rastogi, G.; Tech, J.J.; Coaker, G.L.; Leveau, J.H.J. APCR-based toolbox for the culture-independent quantification of total bacterial abundances in plant environments. J. Microbiol. Meth. 2010, 83, 127-132. [CrossRef]

18. Stiefel, P.; Zambelli, T.; Vorholt, J.A. Isolation of optically targeted single bacteria using FluidFM applied to aerobic anoxygenic phototrophs from the phyllosphere. Appl. Environ. Microbiol. 2013, 79, 4895-4905. [CrossRef] [PubMed]

19. Klenke, F.; Scholler, M. Pflanzenparasitische Kleinpilze: Bestimmungsbuch für Brand-, Rost-, Mehltau-, Flagellatenpilze und Wucherlingsverwandte in Deutschland, Österreich, der Schweiz und Südtirol; Springer: Berlin, Germany, 2015.

20. Durán, P.; Thiergart, T.; Garrido-Oter, R.; Agler, M.; Kemen, E.; Schulze-Lefert, P.; Hacquard, S. Microbial interkingdom interactions in roots promote Arabidopsis survival. Cell 2018, 175, 973-983. [CrossRef]

21. Abayasekara, L.M.; Perera, J.; Chandrasekharan, V.; Gnanam, V.S.; Udunuwara, N.A.; Liyanage, D.S.; Bulathsinhala, N.E.; Adikary, S.; Aluthmuhandiram, J.V.S.; Thanaseelan, C.S.; et al. Detection of bacterial pathogens from clinical specimens using conventional microbial culture and 16S metagenomics: A comparative study. BMC Infect. Dis. 2017, 17, 631. [CrossRef]

22. Hilton, S.K.; Castro-Nallar, E.; Pérez-Losada, M.; Toma, I.; McCaffrey, T.A.; Hoffman, E.P.; Siegel, M.O.; Simon, G.L.; Johnson, W.E.; Crandall, K.A. Metataxonomic and metagenomic approaches vs. culture-dependent techniques for clinical pathology. Front. Microbiol. 2016, 7, 484. [CrossRef]

23. Zapka, C.; Leff, J.; Henley, J.; Tittl, J.; De Nardo, E.; Butler, M.; Griggs, R.; Fierer, N.; Edmonds-Wilson, S. Comparison of standard culture-dependent method to culture-independent method for evaluation of hygiene effects on the hand microbiome. $m$ Bio 2017, 8, e00093-17. [CrossRef]

24. Carraro, L.; Maifreni, M.; Bartolomeoli, I.; Martino, M.E.; Novelli, E.; Frigo, F.; Marino, M.; Cardazzo, B. Comparison of culturedependent and -independent methods for bacterial community monitoring during Montasio cheese manufacturing. Res. Microbiol. 2011, 162, 231-239. [CrossRef]

25. Armanhi, J.S.L.; de Souza, R.S.C.; de Araújo, L.M.; Okura, V.K.; Mieczkowski, P.A.; Imperial, J.; Arruda, P. Multiplex amplicon sequencing for microbe identification in community-based culture collections. Sci. Rep. 2016, 12, 29543. [CrossRef] [PubMed] 
26. Armani, A.; Giusti, A.; Guardone, L.; Castigliego, L.; Gianfaldoni, D.; Guidi, A. Universal primers used for species identification of foodstuff of animal origin: Effects of oligonucleotide tails on PCR amplification and sequencing performance. Food Anal. Methods 2016, 9, 1199-1209. [CrossRef]

27. Zhang, J.; Liu, Y.X.; Guo, X.; Qin, Y.; Garrido-Oter, R.; Schulze-Lefert, P.; Bai, Y. High-throughput cultivation and identification of bacteria from the plant root microbiota. Nat. Protocol. 2021, 16, 988-1012. [CrossRef] [PubMed]

28. Ben Chobba, I.; Elleuch, A.; Ayadi, I.; Khannous, L.; Namsi, A.; Cerqueira, F.; Gharsallah, N.; Vallaeys, T. Fungal diversity in adult date palm (Phoenix dactylifera L.) revealed by culture-dependent and culture-independent approaches. J. Zhejiang Univ. Sci. B 2013, 14, 1084-1099. [CrossRef] [PubMed]

29. Comby, M.; Lacoste, S.; Baillieul, F.; Profizi, C.; Dupont, J. Spatial and temporal variation of cultivable communities of co-occurring endophytes and pathogens in wheat. Front. Microbiol. 2016, 7, 403. [CrossRef] [PubMed]

30. Dissanayake, A.J.; Purahong, W.; Wubet, T.; Hyde, K.D.; Zhang, W.; Xu, H.; Zhang, G.; Fu, C.; Liu, M.; Xing, Q.; et al. Direct comparison of culture-dependent and culture-independent molecular approaches reveal the diversity of fungal endophytic communities in stems of grapevine (Vitis vinifera). Fung Div. 2018, 90, 85-107. [CrossRef]

31. Thiergart, T.; Zgadzaj, R.; Bozsóki, Z.; Garrido-Oter, R.; Radutoiu, S.; Schulze-Lefert, P. Lotus japonicus symbiosis genes impact microbial interactions between symbionts and multikingdom commensal communities. mBio 2019, 10, e01833-19. [CrossRef] [PubMed]

32. Suffert, F.; Sache, I. Relative importance of different types of inoculum to the establishment of Mycosphaerella graminicola in wheat crops in north-west Europe. Plant Pathol. 2011, 60, 878-889. [CrossRef]

33. Fitt, B.D.L.; Brun, H.; Barbetti, M.J.; Rimmer, S.R. World-wide importance of phoma stem canker (Leptosphaeria maculans and L. biglobosa) on oilseed rape (Brassica napus). In Sustainable Strategies for Managing Brassica napus (Oilseed rape) Resistance to Leptosphaeria maculans (phoma stem canker); Fitt, B.D.L., Evans, N., Howlett, B.J., Cooke, B.M., Eds.; Springer: Berlin, Germany, 2006; pp. 3-15.

34. Kerdraon, L.; Barret, M.; Laval, V.; Suffert, F. Differential dynamics of microbial community networks help identify microorganisms interacting with residue-borne pathogens: The case of Zymoseptoria tritici in wheat. Microbiome 2019, 7, 125. [CrossRef] [PubMed]

35. Kerdraon, L.; Barret, M.; Balesdent, M.; Suffert, F.; Laval, V. Impact of a resistance gene against a fungal pathogen on the plant host residue microbiome: The case of the Leptosphaeria maculans-Brassica napus pathosystem. Mol. Plant Pathol. 2020, 21, 1545-1558. [CrossRef] [PubMed]

36. Großkopf, T.; Soyer, O.S. Synthetic microbial communities. Curr. Opin. Microbiol. 2014, 18, 72-77. [CrossRef] [PubMed]

37. Navrátilová, D.; Tláskalová, P.; Kohout, P.; Dřevojan, P.; Fajmon, K.; Chytrý, M.; Baldrian, P. Diversity of fungi and bacteria in species-rich grasslands increases with plant diversity in shoots but not in roots and soil. FEMS Microb. Ecol. 2019, 95 , fiy208. [CrossRef] [PubMed]

38. Tan, X.; Kan, L.; Su, Z.; Liu, X.; Zhang, L. The composition and diversity of soil bacterial and fungal communities along an urban-to-rural gradient in South China. Forests 2019, 10, 797. [CrossRef]

39. Bahram, M.; Netherway, T.; Frioux, C.; Ferretti, P.; Coelho, L.P.; Geisen, S.; Bork, P.; Hildebrand, F. Metagenomic assessment of the global diversity and distribution of bacteria and fungi. Environ. Microb. 2020, 23, 316-326. [CrossRef]

40. Caporaso, J.G.; Lauber, C.L.; Walters, W.A.; Berg-Lyons, D.; Lozupone, C.A.; Turnbaugh, P.J.; Fierer, N.; Knight, R. Global patterns of 16S rRNA diversity at a depth of millions of sequences per sample. Proc. Natl. Acad. Sci. USA 2011, 108, 4516-4522. [CrossRef]

41. Martin, M. CUTADAPT removes adapter sequences from high-throughput sequencing reads. EMBnet. J. 2011, 17, 1. [CrossRef]

42. Callahan, B.J.; McMurdie, P.J.; Rosen, M.J.; Han, A.W.; Johnson, A.J.A.; Holmes, S.P. DADA2: High-resolution sample inference from Illumina amplicon data. Nat. Methods 2016, 13, 581-583. [CrossRef]

43. Wang, Q.; Garrity, G.M.; Tiedge, J.M.; Cole, J.R. Naive Bayesian classifier for rapid assignment of rRNA sequences into the new bacterial taxonomy. Appl. Environ. Microbiol. 2007, 73, 5264-5267. [CrossRef]

44. Davis, N.M.; Proctor, D.M.; Holmes, S.P.; Relman, D.A.; Callahan, B.J. Simple statistical identification and removal of contaminant sequences in marker-gene and metagenomics data. Microbiome 2018, 6, 226. [CrossRef]

45. Schliep, K.P. phangorn: Phylogenetic analysis in R. Bioinformatics 2011, 27, 592-593. [CrossRef]

46. Wright, E.S. DECIPHER: Harnessing local sequence context to improve protein multiple sequence alignment. BMC Bioinform. 2015, 16, 322. [CrossRef]

47. Gardes, M.; Bruns, T.D. ITS primers with enhanced specificity for basidiomycetes-application to the identification of mycorrhizae and rusts. Mol. Ecol. 1993, 2, 113-118. [CrossRef] [PubMed]

48. White, T.J.; Bruns, T.; Lee, S.; Taylor, J. Amplification and direct sequencing of fungal ribosomal RNA genes for phylogenetics. PCR Protoc. Guide Methods Appl. 1990, 18, 315-322.

49. Burland, T.G. DNASTAR's Lasergene sequence analysis software. Methods Mol. Biol. 2000, 132, 71-91.

50. Huerta-Cepas, J.; Serra, F.; Bork, P. ETE 3: Reconstruction, analysis, and visualization of phylogenomic data. Mol. Biol. Evol. 2016, 33, 1635-1638. [CrossRef]

51. Katoh, K.; Standley, D.M. MAFFT Multiple Sequence Alignment Software version 7: Improvements in performance and usability. Mol. Biol. Evol. 2013, 30, 772-780. [CrossRef]

52. Price, M.N.; Dehal, P.S.; Arkin, A.P. FastTree: Computing large minimum evolution trees with profiles instead of a distance matrix. Mol. Biol. Evol. 2009, 26, 1641-1650. [CrossRef] 
53. Letunic, I.; Bork, P. Interactive Tree Of Life (iTOL) v4: Recent updates and new developments. Nucleic Acids Res. $2019,47,256-259$. [CrossRef]

54. Vera, D.I.; Murray, T.D. Occurrence and survival of apothecia of the eyespot pathogens Oculimacula acuformis and O. yallundae on wheat stubble in the U.S. Pacific Northwest. Plant Dis. 2016, 100, 991-995. [CrossRef]

55. Baldani, J.I.; Rouws, L.; Magalhães Cruz, L.; Lopes Olivares, F.; Schmid, M.; Hartmann, A. The Family Oxalobacteraceae. In The Prokaryotes-Alphaproteobacteria and Betaproteobacteria; Rosenberg, E., DeLong, E.F., Lory, S., Stackebrandt, E., Thompson, F., Eds.; Springer: Berlin, Germany, 2014; pp. 919-974.

56. Nishioka, T.; Elsharkawy, M.M.; Suga, H.; Kageyama, K.; Hyakumachi, M.; Shimizu, M. Development of culture medium for the isolation of Flavobacterium and Chryseobacterium from rhizosphere soil. Microbes Environ. 2016, 31, 104-110. [CrossRef]

57. Rinke, C.; Schwientek, P.; Sczyrba, A.; Ivanova, N.N.; Anderson, I.J.; Cheng, J.F.; Darling, A.; Malfatti, S.; Swan, B.K.; Gies, E.A.; et al. Insights into the phylogeny and coding potential of microbial dark matter. Nature 2013, 499, 431-437. [CrossRef] [PubMed]

58. Filippidou, S.; Junier, T.; Wunderlin, T.; Lo, C.C.; Li, P.E.; Chain, P.S.; Junier, P. Under-detection of endospore-forming Firmicutes in metagenomic data. Comput. Struct. Biotech. J. 2015, 13, 299-306. [CrossRef]

59. Evtushenko, L.I.; Takeuchi, M.T. The Family Microbacteriaceae. In The Prokaryotes-Alphaproteobacteria and Betaproteobacteria; Rosenberg, E., DeLong, E.F., Lory, S., Stackebrandt, E., Thompson, F., Eds.; Springer: Berlin, Germany, 2017; pp. 1020-1098.

60. Hamad, I.; Ranque, S.; Azhar, E.I.; Yasir, M.; Jiman-Fatani, A.A.; Tissot-Dupont, H.; Raoult, D.; Bittar, F. Culturomics and amplicon-based metagenomic approaches for the study of fungal population in human gut microbiota. Sci. Rep. 2017, 7, 16788. [CrossRef]

61. Krehenwinkel, H.; Pomerantz, A.; Henderson, J.B.; Kennedy, S.R.; Lim, J.Y.; Swamy, V.; Shoobridge, J.D.; Graham, N.; Patel, N.H.; Gillespie, R.G.; et al. Nanopore sequencing of long ribosomal DNA amplicons enables portable and simple biodiversity assessments with high phylogenetic resolution across broad taxonomic scale. GigaScience 2019, 8, giz006. [CrossRef] [PubMed]

62. Heeger, F.; Bourne, E.C.; Baschien, C.; Yurkov, A.; Bunk, B.; Spröer, C.; Overmann, J.; Mazzoni, C.J.; Monaghan, M.T. Long-read DNA metabarcoding of ribosomal RNA in the analysis of fungi from aquatic environments. Mol. Ecol. Resour. 2018, 18, 1500-1514. [CrossRef]

63. Raja, H.A.; Miller, A.N.; Pearce, C.J.; Oberlies, N.H. Fungal identification using molecular tools: A primer for the natural products research community. J. Nat. Prod. 2017, 80, 756-770. [CrossRef]

64. Callahan, B.J.; Wong, J.; Heiner, C.; Oh, S.; Theriot, C.M.; Gulati, A.S.; McGill, S.K.; Dougherty, M.K. High-throughput amplicon sequencing of the full-length 16S rRNA gene with single-nucleotide resolution. Nucleic Acids Res. 2019, 47, e103. [CrossRef]

65. Barret, M.; Briand, M.; Bonneau, S.; Préveaux, A.; Valière, S.; Bouchez, O.; Hunault, G.; Simoneau, P.; Jacques, M.-A. Emergence shapes the structure of the seed microbiota. Appl. Environ. Microbiol. 2015, 81, 1257-1266. [CrossRef] [PubMed]

66. El-Tarabily, K.A.; Sivasithamparam, K. Potential of yeasts as biocontrol agents of soil-borne fungal plant pathogens and as plant growth promoters. Mycoscience 2006, 47, 25-35. [CrossRef]

67. Sergaki, C.; Lagunas, B.; Lidbury, I.; Gifford, M.L.; Schäfer, P. Challenges and approaches in microbiome research: From fundamental to applied. Front. Plant Sci. 2018, 9, 1205. [CrossRef]

68. Liu, Y.X.; Qin, Y.; Bai, Y. Reductionist synthetic community approaches in root microbiome research. Curr. Opin. Microbiol. 2019, 49, 97-102. [CrossRef]

69. Zhuang, L.; Li, Y.; Wang, Z.; Yu, Y.; Zhang, N.; Yang, C.; Zeng, Q.; Wang, Q. Synthetic community with six Pseudomonas strains screened from garlic rhizosphere microbiome promotes plant growth. Microb. Biotech. 2020, 14, 488-502. [CrossRef] [PubMed]

70. Martiny, A.C. High proportions of bacteria are culturable across major biomes. ISME 2019, 13, 2125-2128. [CrossRef]

71. Steen, A.D.; Crits-Christoph, A.; Carini, P.; DeAngelis, K.M.; Fierer, N.; Lloyd, K.G.; Thrash, J.C. High proportions of bacteria and archaea across most biomes remain uncultured. ISME J. 2019, 13, 3126-3130. [CrossRef] [PubMed]

72. Bai, Y.; Müller, D.B.; Srinivas, G.; Garrido-Oter, R.; Potthoff, E.; Rott, M.; Dombrowski, N.; Münch, P.C.; Spaepen, S.; RemusEmsermann, M.; et al. Functional overlap of the Arabidopsis leaf and root microbiota. Nature 2015, 528, 364-369. [CrossRef] 